\title{
Production and Quality Evaluation of Young Thai Jasmine Rice Flake Using Drum Dryer
}

\author{
Kullamethee Piyarach ${ }^{1 *}$, Phumpakdee Sutham ${ }^{1}$, Khong-im Pongsiri ${ }^{1}$, Alqurashi Randah ${ }^{2}$ and Suwan \\ Teerawan ${ }^{1}$ \\ ${ }^{1}$ Department of Innovation and Product development Technology, Faculty of Agro-industry, \\ King Mongkut's University of Technology North Bangkok, 129 Moo21 Nernhom, Prachinburi, 25230, Thailand \\ ${ }^{2}$ Department of Food and Nutrition, College of Agriculture and Food Sciences, King Faisal University, Al-Ahsa 31982, Saudi Arabia
}

\begin{abstract}
Immature rice grains contain high bioactive compounds. Drying has been used for the food preservation and reduction of agricultural waste. This study aimed to produce the rice flake from young Thai Jasmine rice grain (light green and soft texture) using double drum dryer at $120^{\circ} \mathrm{C}$, drum rotation speed $0.5,0.7$, and $0.9 \mathrm{rpm}$, and the ratios of grain to water of 1:3 1:5 and 1:7w/w. The nutritional properties of rice flake were also investigated. The results showed that increasing rotation speed gives a significant effect on the higher moisture content and water activity. Using lower water ratio with slowing down rotation speed resulted in higher brightness of the flake products including quicker dehydration. The selected optimal condition of preparing rice flake was 1:5 w/w young grain to water at $0.5 \mathrm{rpm}$ drum speed. The flake contains fat, protein, carbohydrate, ash, approximately $0.004 \%, 6.140 \%, 88.686 \%$ and $0.92 \%$, respectively. Phenolic content and antioxidant capacity of rice flake were decreased after drying. Total phenolic content of the flake was $280.931 \mathrm{mg}$ GAE/g and antioxidant activities; DPPH, FRAP and ABTS were 254.158, 123.172 and $372.298 \mathrm{mg}$ TE/g, respectively. Young rice flake remains a great nutritional value which has potential in the food industry.
\end{abstract}

Keyword. Young rice grain, Thai Jasmine rice, Double drum dryer, Rice flake, Total phenolic, Antioxidant activity

\section{Introduction}

Rice has been the main staple food of choice for more than half of the world population and important to Thailand's economy especially Thai Jasmine rice (Hom Mali 105) variety (Oryzae sativa. L). Thailand is moving toward industrialization and production of agricultural products has declined including rice production sector; accordingly, the gross domestic product (GDP) has been decreasing. Therefore, an aim to increase value added of rice and nutritional value becomes a priority. At the moment, utilization of rice in the industries as a composition in processed foods and healthy foods products tends to increase. Among Asian countries where rice is mainly consumed as carbohydrate source, Thai's jasmine rice is very desirable due to its aromas and is strongly demanded for an import. Development of rice products is an alternative to increase an income for Thai farmers, yet marketing strategy and further research is essential [1].

Interestingly, immature kernel is traditionally used as nourishing food in most Asian countries. Thailand and Vietnam are commonly used for producing as a snack food (flatted milky rice mixed with sugar and scraped coconut) on the special occasion. The milky stage of the young rice was reported with high numbers of bioactive compounds than its mature stage, which observed that when developed the starch contained in rice is hence to degrade the bioactive compounds in rice [2-4]. A previous study by S. Butsat et al. [5] and S. Jiamyangyuen et al. [3] was described the 5 stages of rice grain development which include the "flowering" as the first stage (age 0-7 days) that has small and flat endosperm with the green colour of the seed coat. The second stage "milk grain or immature grain or young grain" (age 8-14 days after post-anthesis) (Figure 1(a)). In the second stage the endosperm begins forming milky liquid and increased the size of the rice and in this stage, the colour of the coat starts to change dependent on the cultivars of the rice. The third stage is "dough grain" (age 15-21 days after post-anthesis) which is the milky liquid of the endosperm that starts to become solidify into sticky white type. Also, in this stage, the endosperm continues to increase and become bigger and the colour of the seed coat becomes clearer than in the previous stage. The Fourth stage called "mature" (age 22-28 days after post-anthesis) which the grain become mature and hard also the endosperm is increased their size more. In the final stage called "fully ripe" (age 29-35 days after post-anthesis) which the grain becomes fully mature and hard, and the endosperm size increased to the largest size. The colour of that seed coat strongly presenting the colour of the other types of rice cultivars. However, the stage of immature milky of rice (second stage of rice grain development) has not the previous study well.

The study of bioactive compounds in rice during grain development was found that two developing rice grains (waxy red rice and non-waxy rice) contain higher bioactive compounds, total phenolics, and total flavonoids than its mature grain. The high content of free and soluble ferulic acids, $\alpha$-Tocopherol, $\alpha$ - and $\beta$ tocotrienol, dietary fiber, are abundant in the early development stage of brown grains at day 15-18 after anthesis [6]. Rice grains at the stage of immature contain

Corresponding author: piyarach.k@agro.kmutnb.ac.th 
a high number of bioactive compounds and antioxidant activities which have potential health benefits and can apply in the food industry [7]. At present, people's lifestyle has changed due to the speed of life and they prefer to prepare and consumed food quickly especially in a breakfast meal. Therefore, in the food industry, the demand of cereals and food that contained fiber, proteins, and antioxidant activity is increasing dramatically. Some of cereals are available in the markets such as legumes, buckwheat, semolina, barley, rye, oats, and rice [8].

Nowadays, rice processing is the trend which commonly using as a breakfast cereals dish mixed with milk or water and added flavorings such as honey, dried fruit, sugar, or syrup. Alternatively, mixing rice products with vegetable and species is an option to create savory dishes. To be able to fulfill the demand of some people who focus on healthy lifestyle, rice is processed into the form of porridge for the ease to use and lower calories in the meals [9-10]. The rice porridges usually recooking and made as dried flakes (Figure 1(b)) and powder before mixing with other ingredients. These flakes of the rice swell after mix with a liquid such as milk or warm water [10]. Drying cereals and rice is one of the main important processes which have affected the quality of the final product. It can be affected the concentration of bioactive compounds and other nutrients also the textures of the product. Drum drying is a technique (short-time with high-temperature) widely uses in the food industry particularly for heat-sensitive products that uses the drying of a thin film of solution or suspension on a heated drum and subsequent removal of the film of dry solids [11]. Double drum dryer is generally used for preservation in the food industries because this equipment is suitable for a wide range of materials. This method is one of the most appropriate techniques for using liquid feedstock form (solution, slurry, and pastes) and providing the final product such as powders or flakes when compared with other drying technology. Moreover, this process is effortless and economical method during the operation for pre-gelatinization [1214]. Energy consumption of liquid type of feedstock such as drum dryer, fluid bed dryer, and spray dryer is in the range between 3,200-6,500, 4,000-6,000, and 4,500$11,500\left(\mathrm{~kJ} / \mathrm{kg}\right.$ of $\mathrm{H}_{2} \mathrm{O}$ evaporated), respectively in the common industrial dryers [14]. C. Córdova et al [15] demonstrated that drum drying has great potential to dehydrate broccoli pulp and maintained functional compound such as sulforaphane, phenolic compounds, and antioxidant activities. A study by K. Ruttarattanamongkol et al. [16] reported that after decreasing drum speed and increasing drum drying temperature, the moisture content of the sweet potato flour was declined. On the contrary higher temperature of drum drying significantly resulted in the lower total phenolic content and antioxidant activity. This was also the observation of $\mathrm{P}$. Wiriyawattana et al. [17] that addressed the effects of drum drying on the physical and antioxidant properties of pregelatinized rice berry flour. The finding has shown that drying resulted in reduction of both total phenolic content and antioxidant activity.
The developing rice grains have a relatively high amount of phytochemical sources, especially young rice grain at the milky period that would be suitable for healthy food applications such as porridge, cereal, and soup. Early harvesting rice grain at the immature stage instead of the fully ripe would be alternative process for resources conservation such as water consumption, land use, soil organic matter and fertilizer [18, 19]. In addition to high nourishment of immature rice grain that causes short shelf life, colour changing, microbial contamination affects its marketing value. Therefore, dehydration process has been widely used in order to preserve raw materials and reduce food waste and loss of agricultural resources $[14,15,19]$. The optimal condition to produce Thai Jasmine rice (milky period) flake using a double drum dryer is therefore interested. We determined the ratios of young brown rice grain to water and drum rotation speed on rice flake qualities. The physical, chemical, and microbial properties of young rice flakes were also estimated. This production would be useful for the rice farm owner who would like to value-added their agricultural product as well as the food industry that desires to produce the instant products from immature kernel.
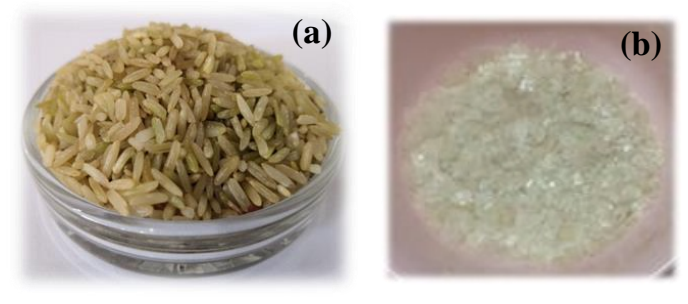

Fig. 1. Images of (a) immature brown rice grain and (b) the thin film of rice flake.

\section{Materials and Methods}

\subsection{Materials}

Immature stage of Thai Jasmine rice 105 or Khao Dawk Mali 105 (Oryza sativa L.) (Figure 1(a)), was obtained from Ban-nakham organic rice field (community enterprise network) in Ban-nakham, Kabinburi, Prachinburi province, Thailand. The stage of young grain development was collected at 8-14 days after the flowering day. Brown young rice grain was separated from hull using machine and kept in polyethylene vacuum bag covering with aluminum foil at room temperature until use.

\subsection{Chemicals}

Reagents for antioxidant assays and phenolic standards such as Gallic acid, Folin-Ciocalteu, 2,2'azinobis (3ethylbenzothaiazoline-6 -sulfonic acid) (ABTS) were purchased form Sigma-Aldrichz, USA. 2,2-diphenyl1picrylhydrazyl (DPPH) and Trolox were obtained from Sigma-Aldrichz, Germany and Russia, respectively. Other unmarked reagents were used analytical grade. 


\subsection{Drying experiment}

Before drying process, young brown rice was prepared by soaking with water for about $4 \mathrm{hrs}$. Then, draining off water and preparation the ratios of young rice to water at 1:3 $1: 5$ and $1: 7 \mathrm{w} / \mathrm{w}$ and each treatment was blended for 5 mins using food processor (Sharp, EM-ICE2, Thailand) at high-speed level (17,000 rpm). After that, the slurry was pre-heat using electric hot plate $(400 \mathrm{~W})$ (Master Cooking, MC-1, France) at middle heat level for about 30 mins. $\left(90 \pm 2^{\circ} \mathrm{C}\right)$. The pregelatinized slurry was feed in double drum dryer (electric heating, DD-D6L12HT-INV, Thailand) at $112 \pm 5 \mathrm{~g}$ feed rate with the different of drum rotation speed (0.5, 0.7 and $0.9 \mathrm{rpm})$, $0.25 \mathrm{~mm}$. of the gap between drums and $120{ }^{\circ} \mathrm{C}$ of drying temperature. The dried flake of young brown rice (Figure 1(b)) was collected as a thin film from the drum surface. Procedure of the drying experiment presented in Figure 2.

\subsection{Proximate composition analysis, physical and microbial properties}

Proximate composition analysis (moisture content, protein, fiber, ash and fat contents) of the brown immature rice flake were performed following the official methods described by Association of Official Analytical Chemistry (AOAC 2005) with three replications. Water activity meter (AQUA 3TE, USA) was used for water activity evaluation. The colour of the sample was measured using Hunterlab MiniScan (ColorFlex, USA) and reported as CIE system (International Commis-sion on Illumination). $L^{*}(0=$ black, $100=$ white $), a^{*}\left(-\mathrm{a}^{*}=\right.$ greenness, $+\mathrm{a}^{*}=$ redness $)$, and $b^{*}\left(-\mathrm{b}^{*}=\right.$ blueness, $+\mathrm{b}^{*}=$ yellowness $)$ parameters indicated lightness, redness/greenness, and yellowness /blueness, respectively. Color measurement was carried out in three replicates for each treatment.

Total viable count and yeast and mold test were used as the microbiological assessment to monitor the young rice flake product. $1 \mathrm{~g}$ of sample was collected aseptically in a stomacher bag and 9 volumes of peptone solution $(0.01 \%, \mathrm{w} / \mathrm{v})$ were added. After homogenization in a Stomacher blender for 2 mins, a series of tenfold dilutions were made using the same solution. According to Thai Industrial Standard No. 315-2548 of the instant rice porridge (congee), the optimal conditions were expected to reach the final moisture content less than $7 \%$. Moreover, the microbial standard of the product was not exceed the level of total microbial count $<1 \times 10^{5}$ $\mathrm{CFU} / \mathrm{g}$, yeast and mold $<100 \mathrm{CFU} / \mathrm{g}$. Thai Community product Standard No.1068/2558 of the instant drink brown rice was used for indication water activity less than 0.6 in order to maintain the desirable quality of food products and their shelf-life.

\subsection{Water absorption index (WAI) and water soluble index (WSI)}

The water absorption index (WAI) and water soluble index (WSI) properties of the young rice flake was determined as described by R. A. Anderson, et al [20] with some modification. Briefly, $2.5 \mathrm{~g}$ rice flake (weight of rice flake; Wrf) was suspended in distilled water at temperature $30{ }^{\circ} \mathrm{C}$ for 30 mins., gently stirred and centrifuged at 2,200 rpm for 15 mins. The supernatant was decanted into an evaporating dish. This supernatant was then dried at $105{ }^{\circ} \mathrm{C}$ until constant weight and the weight of dissolved solids (Wds) in the supernatant was recorded. The remaining sediment in the centrifuge tube was weighted (weight of remaining sediment; Wrs). WAI and WSI values were calculated according to Equations (1) and (2), respectively.

$$
\begin{aligned}
\text { WAI } & =\frac{\mathrm{Wrs}}{\operatorname{Wrf}(\mathrm{g})} \\
\mathrm{WSI}(\%) & =\frac{\mathrm{Wds}}{\mathrm{Wrf}} \times 100
\end{aligned}
$$

\subsection{Extraction of bioactive compounds}

Rice samples (young brown rice grain and the dried rice flake) was extracted for determination the bioactive compound as described by S. Jiamyangyuen et al. [3]. The rice samples were freeze dried at $-40{ }^{\circ} \mathrm{C}$ for $4 \mathrm{hrs}$ and ground into powder. The powder of rice samples was kept at $-40{ }^{\circ} \mathrm{C}$ before use. $0.5 \mathrm{~g}$ of each sample (rice grain and young rice flake) was extracted with $20 \mathrm{ml}$. acidified methanol/1 $\mathrm{N} \mathrm{HCl}$ in water $(85: 15$ by volume) in centrifuge tube for 1 hour and vortexed for 2 mins. The soluble extract was centrifuged at $5,000 \mathrm{rpm}$ for 10 mins and the supernatant was collected. The residue was re-extracted twice using the same method and all supernatants were pooled. The supernatant was evaporated under rotary evaporator at $40{ }^{\circ} \mathrm{C}$ for $5 \mathrm{hrs}$. and made up completely dry using hot air oven in order to concentrate the extract and eliminate the solvent. The concentrated extract was redissolved to $15 \mathrm{mg} / \mathrm{ml}$ by adding methanol. The solution was then stored at $-40^{\circ} \mathrm{C}$ for further analysis. The rice extract was used for determination total phenolic content and antioxidant activity (2,2-diphenyl-1 picrylhydrazyl (DPPH), Ferric ion reducing antioxidant power (FRAP) and 2,2-azinobis 3-ethylbenzthiazoline-6-sulphonic acid (ABTS) radical scavenging assay)

\subsection{Determination of total phenolic content (TPC)}

The TPC was analyzed through the reducing power against Folin-Ciocalteu using the method of O. Folin and V. Ciocalteu [21] and P. Wiriyawattana et al. [17] with minor modification. $0.4 \mathrm{ml}$ of rice sample extracts were mixed with $2 \mathrm{ml}$ of freshly prepared diluted FolinCiocalteu reagent $(10 \% \mathrm{v} / \mathrm{v})$ and incubated at room temperature for 5 mins. After mixing, $1.6 \mu \mathrm{l}$ of sodium carbonate aqueous solution $(5 \% \mathrm{w} / \mathrm{v})$ was added. The reagent was then stored under dark condition at room temperature for 30 mins to allow the completion of the reaction. The intensity of the developed blue colour was 
measured at $765 \mathrm{~nm}$ using a microplate reader (Accu Reader, M965/M965+, Taiwan). Different concentration of gallic acid dissolved in methanol were used to prepare the standard curve $\left(R^{2}=0.9929\right)$. The result of TPC was reported as milligram of gallic acid equivalent $(\mathrm{mg}$ GAE/100 g dry weight (dw)). Estimation of the TPC was carried out in triplicate.

\subsection{Determination of DPPH scavenging activity}

The scavenging capacity of the rice sample extracts against 2,2-diphenyl-1picrylhydrazyl (DPPH) radical was measured according to W. Daiponmak et al. [22]. with slight modification. Briefly, $100 \mu \mathrm{l}$ of extract solution was mixed with 2,900 $\mu$ DPPH solution (100 $\mu \mathrm{M})$. The mixture was shaken vigorously and incubated in dark condition at room temperature for 30 mins. After the reaction, the absorbance (Abs) was measured at 517 $\mathrm{nm}$ using a microplate reader. Trolox was used as a standard antioxidant and the result was expressed as milligram Trolox equivalent (mg TE/g dw). Estimation of the DPPH activity was carried out in triplicate. The scavenging activity was calculated using the formula.

scavenging activity $(\%)=\frac{A b s_{\text {control }}-\text { Abs }_{\text {sample }}}{A b s_{\text {control }}} \times 100$

\subsection{Determination of FRAP scavenging activity}

Ferric ion reducing antioxidant power (FRAP) of the rice extract was analyzed based on Benzie and strain [23] and S. Jiamyangyuen et al. [3] with some modification. The reagent of FRAP was freshly prepared as following reagents: $300 \mathrm{mM}$ acetate buffer $(\mathrm{pH} 3.6), 10 \mathrm{mM}$ of 2,4,6-Tripyridyl-s-triazine (TPTZ) solution in $40 \mathrm{mM}$ $\mathrm{HCL}$, and $20 \mathrm{mM}$ ferric chloride $\left(\mathrm{FeCl}_{3}\right)$ in methanol, at ratio of 10:1:1 by volume. $0.1 \mathrm{ml}$ extract solution and 2 ml FRAP reagent were mixed and incubated for 30 mins. The developed blue solution was measured at $595 \mathrm{~nm}$ using microplate reader. Trolox was used as a standard reference and the result was converted as milligram trolox equivalent (mg TE/100 $\mathrm{g} \mathrm{dw}$ ). The scavenging activity was then calculated using the formula.

$$
\text { scavenging activity }(\%)=\frac{A b s_{\text {control }}-A b s_{\text {sample }}}{A b s_{\text {control }}} \times 100
$$

\subsection{Determination of ABTS scavenging activity}

2,2-azinobis 3-ethylbenzthiazoline-6-sulphonic acid (ABTS) radical scavenging assay of rice extracts was determined using a modification of the procedure described by Re et al. [24] and W. Daiponmark, et al. [22]. The stock solution was prepared with 2:1 volumes of $7 \mathrm{mM}$ ABTS solution and $2.45 \mathrm{mM}$ potassium persulfate solution. The mixture was stand in the dark condition at room temperature for $12 \mathrm{hrs}$. The working solution was freshly prepared for each assay by diluting the stock solution with $95 \%$ ethanol until the absorbance at $734 \mathrm{~nm}$ was measured $0.670-0.730 .1 \mathrm{ml}$ of the rice extract was added into $2 \mathrm{ml}$ of the ABTS working solution and mixed thoroughly. The decrease in absorbance at $734 \mathrm{~nm}$ was then recorded and expressed as mg Trolox/gram extract dry weight. The scavenging activity was estimated based on the percentage of ABTS radicals scavenged according to Equation.

scavenging activity $(\%)=\frac{A b s_{\text {control }}-\text { Abs }}{\text { sample }} \times 100$

\subsection{Statistic}

The experiment was conducted in a complete randomized design with three replications. The results were subjected to analysis of variance and mean comparison by One-Way ANOVA followed by Duncan's multiple range tests at $95 \%$ confidence level $(p$ $\leq 0.05$ ), in order to determine any differences among treatments The paired Student's t-test were also used in order to determine any significance of the differences in the physical, chemical, and microbial properties between rice grain and rice flake. The data was performed using SPSS.

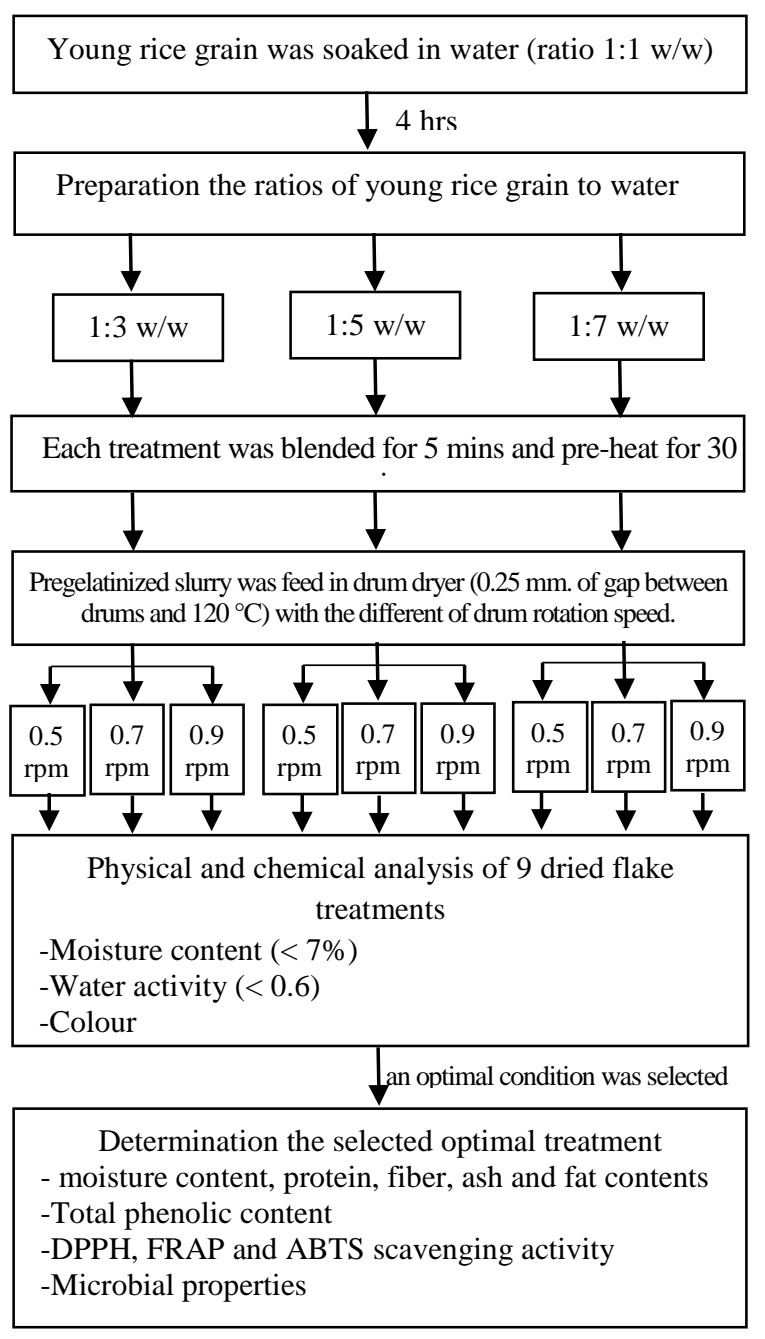

Fig. 2. Flow diagram of the experiment. 


\section{Results and discussion}

\subsection{Effect of young rice grain to water ratio and drum rotation speeds on physicals and chemical properties of rice flake}

After conducting the drying experiments, the results showed that increasing of rotation speed gives significant effect $(p<0.05)$ on the higher value of moisture content and water activity (Table 1). Application of lower water content with lower speed of rotation resulted in faster dehydration. Decreasing speed of rotation used in drum dryer allowed rice slurry to contact the surface of drum dryer in longer period of time and this, consequently, increased the dehydration rate of water in rice film. The water activity of all treatments was not exceeded the standard. The lowest water activity was $0.189 \pm 0.002$ (treatment No. 4 at ratio $1: 5,0.5 \mathrm{rpm})$. The lowest moisture content of the product was $3.28 \pm 0.13 \%$ (treatment No. 1 at ratio $1: 3$, $0.5 \mathrm{rpm}$ ). According to Thai Industrial Standard No. 3152548 and Thai Community product Standard No.1068/2558, the requirement moisture content of the young rice flake and water activity were less than $7 \%$ and 0.6 , respectively. The water activity is a crucial characteristic for shelf life of the product. Therefore, the optimum condition of young rice flake from the study could be the treatments No. 1-5 and No. 7-8.

Results in Table 1 indicated that the colour of rice flake tends to be lighter when decreasing the speed of drum rotation and increasing amount of rice grain. All flake treatments were presented the lightness $\left(L^{*}\right)$ range between $31.89 \pm 0.24$ to $46.40 \pm 0.36$, redness $\left(a^{*}\right)$ between $1.27 \pm 0.03$ to $1.85 \pm 0.03$ and yellowness $\left(b^{*}\right)$ between $7.77 \pm 0.13$ to $14.82 \pm 0.07$. The colour of rice flake treatments differs from the young rice grain with lightness, redness, and yellowness as $26.10 \pm 0.32$, $1.05 \pm 0.06$ and $7.61 \pm 0.35$, respectively. Changes in colour of the treatments were possibly caused by the alteration of contacted surface areas in materials when exposed to high temperature during drum dryer process. In addition, chemical reaction such as Millard reaction induced by thermal treatment is one of the factors affecting the change in colour of the products. When temperature and heating time was increased, this browning reaction was also elevated accordingly. The colour quality and nutritional properties of rice is affected directly by thermal processing $[11,16]$. After drum drying, WAI of the treatments with high amount of rice grain were significantly $(\mathrm{p}<0.05)$ higher than those with the low grain content. In addition, the samples with high rice grain ratio were significantly decreased in water soluble index (WSI). The rice grain content effected the water absorption index (WAI) and WSI. While WAI and WSI value were not affected by rotation speeds. P. Wiriyawattana et al. [17] investigated the effects of drum drying on the physical and antioxidant properties of pregelatinized riceberry flour and their results demonstrated that the WSI and swelling power of the samples were significantly higher than the unheated rice flour. WAI was used as an indicator to measure water volume inside the granule or starch polymer after maximum absorption of water. WSI increased in parallel with moisture content that is mostly due to proper gelatinization and lateral expansion of the starch [25]. To determine the rate of penetration of water into solid particles and diffusion of soluble components outside the particles, the WSI is a common measurement to obtain these values. The common evaluation is to measure the degradation of molecular components generated by starch degradation which are easily dissolved. Therefore, the solubilization of power is indicated by an increase of WSI value [26].

The important parameter such as feed rate, thickness of film, drum speed, and drum surface temperature play the crucial role to maintain uniformity of the film on drum surface as well as to maximize the consistency of final moisture content in pregelatinized rice $[27,28]$. From the results, the optimal condition of producing young rice flake product using drum dryer was retrieved from treatments No. 1, 2, 4 and 5. The treatment No. 4 yielding the lowest water activity was selected for further study including physical, chemical, and microbial properties.

Table 1. Moisture content, water activity, colour, water absorption index and water solubility index of rice flake in different treatments.

\begin{tabular}{|c|c|c|c|c|c|c|c|c|c|}
\hline \multirow{2}{*}{$\begin{array}{c}\text { Sample } \\
\text { No. }\end{array}$} & \multirow{2}{*}{$\begin{array}{c}\text { Ratio } \\
\text { (Grain:Water) }\end{array}$} & \multirow{2}{*}{$\begin{array}{l}\text { Rotation } \\
\text { speed } \\
\text { (rpm) }\end{array}$} & \multirow{2}{*}{$\begin{array}{c}\% \\
\text { Moisture } \\
\text { Content }\end{array}$} & \multirow{2}{*}{$\mathbf{a}_{\mathrm{w}}$} & \multicolumn{3}{|c|}{ Colour } & \multirow{2}{*}{ WAI } & \multirow{2}{*}{$\begin{array}{l}\text { WSI } \\
(\%)\end{array}$} \\
\hline & & & & & $\mathbf{L}^{*}$ & $a^{*}$ & $\mathbf{b}^{*}$ & & \\
\hline 1 & $1: 3$ & 0.5 & $3.28 \pm 0.13^{\mathrm{f}}$ & $0.238 \pm 0.003^{\mathrm{f}}$ & $46.40 \pm 0.36^{\mathrm{a}}$ & $1.85 \pm 0.03^{\mathrm{a}}$ & $14.82 \pm 0.07^{\mathrm{a}}$ & $2.56 \pm 0.04^{\mathrm{a}}$ & $4.99 \pm 0.57^{f}$ \\
\hline 2 & $1: 3$ & 0.7 & $3.66 \pm 0.17^{\mathrm{f}}$ & $0.413 \pm 0.001^{\mathrm{e}}$ & $40.73 \pm 0.16^{\text {de }}$ & $1.35 \pm 0.07^{\mathrm{f}}$ & $10.29 \pm 0.34^{\mathrm{d}}$ & $2.55 \pm 0.06^{\mathrm{a}}$ & $5.43 \pm 0.06^{\mathrm{ef}}$ \\
\hline 3 & $1: 3$ & 0.9 & $6.42 \pm 0.18^{b}$ & $0.441 \pm 0.002^{\mathrm{d}}$ & $37.70 \pm 5.94^{\mathrm{e}}$ & $1.57 \pm 0.05^{\mathrm{c}}$ & $9.72 \pm 0.13^{\mathrm{e}}$ & $2.43 \pm 0.05^{\mathrm{b}}$ & $5.60 \pm 0.33^{\mathrm{e}}$ \\
\hline 4 & $1: 5$ & 0.5 & $4.25 \pm 0.13^{\mathrm{e}}$ & $0.189 \pm 0.002^{\mathrm{g}}$ & $44.79 \pm 0.36^{\mathrm{abc}}$ & $1.46 \pm 0.01^{\mathrm{de}}$ & $12.17 \pm 0.16^{\mathrm{b}}$ & $2.37 \pm 0.02^{\mathrm{bc}}$ & $6.31 \pm 0.19^{\mathrm{d}}$ \\
\hline 5 & $1: 5$ & 0.7 & $5.44 \pm 0.37^{\mathrm{c}}$ & $0.459 \pm 0.002^{\mathrm{c}}$ & $41.24 \pm 0.33^{\text {cde }}$ & $1.58 \pm 0.01^{\mathrm{c}}$ & $11.15 \pm 0.16^{\mathrm{c}}$ & $2.37 \pm 0.08^{\mathrm{bc}}$ & $6.73 \pm 0.09^{\text {cd }}$ \\
\hline 6 & $1: 5$ & 0.9 & $7.50 \pm 0.38^{\mathrm{a}}$ & $0.519 \pm 0.003^{\mathrm{b}}$ & $44.58 \pm 0.47^{\mathrm{abc}}$ & $1.44 \pm 0.05^{\mathrm{e}}$ & $11.34 \pm 0.02^{\mathrm{c}}$ & $2.31 \pm 0.06^{c}$ & $6.99 \pm 0.24^{c}$ \\
\hline 7 & $1: 7$ & 0.5 & $4.94 \pm 0.34^{\mathrm{d}}$ & $0.234 \pm 0.008^{\mathrm{f}}$ & $31.89 \pm 0.24^{\mathrm{f}}$ & $1.27 \pm 0.03^{\mathrm{g}}$ & $7.77 \pm 0.13^{\mathrm{f}}$ & $2.07 \pm 0.05^{\mathrm{d}}$ & $7.92 \pm 0.12^{b}$ \\
\hline 8 & $1: 7$ & 0.7 & $6.25 \pm 0.14^{\mathrm{b}}$ & $0.442 \pm 0.010^{\mathrm{d}}$ & $42.24 \pm 0.10^{\text {bcd }}$ & $1.75 \pm 0.03^{b}$ & $11.14 \pm 0.07^{\mathrm{c}}$ & $2.09 \pm 0.05^{\mathrm{d}}$ & $9.36 \pm 0.45^{\mathrm{a}}$ \\
\hline 9 & $1: 7$ & 0.9 & $7.64 \pm 0.30^{\mathrm{a}}$ & $0.529 \pm 0.003^{\mathrm{a}}$ & $45.50 \pm 0.55^{\mathrm{ab}}$ & $1.52 \pm 0.03^{\text {cd }}$ & $12.13 \pm 0.8^{b}$ & $2.05 \pm 0.02^{\mathrm{d}}$ & $9.56 \pm 0.17^{\mathrm{a}}$ \\
\hline
\end{tabular}

Data were presented as mean values. ${ }^{a, b}$ values in the same column followed by different lowercase superscript letters are significantly different of each product treatment. 


\subsection{Physical, chemical and microbial properties of young rice flake}

Immature kernel as show in Table $2, L^{*}, a^{*}$ and $b^{*}$ values were $26.10 \pm 0.32,1.05 \pm 0.06$ and $7.61 \pm 0.35$, respectively. Approximately, composition of immature kernel consisted of $1.43 \pm 0.12 \%$ ash, $6.98 \pm 0.57 \%$ protein, $0.107 \pm 0.002 \%$ fat and $81.53 \%$ carbohydrate. The grain had $8.75 \pm 0.19 \%$ moisture content, under the Thai Hom Mali rice standard (moisture content less than 14\%, Thai Agricultural Standard (TAS 4000-2017)) microbial properties of the grain were also evaluated as $1 \times 10^{3} \mathrm{CFU} / \mathrm{g}$ total plate count and $3 \times 10^{2} \mathrm{CFU} / \mathrm{g}$ yeast/mold.

In the present investigation, the results showed significant $(\mathrm{p}<0.05)$ changes in the color values of selected immature rice flake product compared to the immature kernel (Table 2). The flake product was lighter (higher $L^{*}$ value), redder (higher $a^{*}$ value) and yellower (higher $b^{*}$ value) than the immature kernel. The possible changed colour of the young rice flake was because preheat of rice slurry exposed to the high temperature during the drum drying process. Moreover, using thermal treatment induces non-enzymatic browning that can lead to the formation of the brown colour. The browning colour reaction was enhancing by increased temperature degree and heating time. Rice colour also can be affected it and degrade during thermal processing which affects the nutritional properties of the rice [26, 29].

For the evaluation the total phenolic content (Table 2) and antioxidant free radical scavenging properties (Table 2 and Figure 3), the results presented immature kernel contain high concentration of phenolic compound (347.965 $\pm 81.522 \mathrm{mg} \mathrm{GAE} / \mathrm{g})$ and rich in antioxidant activities (DPPH, FRAP and ABTS were 254.158, 123.172 and $372.298 \mathrm{mg} \mathrm{TE} / \mathrm{g}$, respectively). There are several studies reveal that Thai rice cultivars enriched with bioactive compound content and antioxidant capacities. This trend is similar the previous study of $\mathrm{W}$. Daiponmark et al. [30] found high value of total phenolic compound and antioxidant activities of four white grain of Thai rice cultivar. White rice varieties contain total phenolic content range between 24.8641.73 (mg GAE/g extract $\mathrm{dw}$ ), ABTS range between 39.49-52.24 (mg Trolox/g extract $\mathrm{dw}$ ) and DPPH range between 15.75-23.68 (mg Trolox/g extract $\mathrm{dw}$ ). In addition, previous study has shown that young rice (red rice) at stages 2-3 has high antioxidant activity using FRAP assay [3]. After drum drying total phenolic content and antioxidant activity of the young rice flake significantly decreased $(\mathrm{p}<0.05)$. The flake product remains total phenolic content $280.930 \pm 3.995 \mathrm{mg}$ GAE/g) and DPPH, FRAP and ABTS were $254.158 \pm 7.644,123.172 \pm 3.137$ and $372.298 \pm 3.334 \mathrm{mg}$ $\mathrm{TE} / \mathrm{g}$, respectively. This was attributed to the degradation of phenolic compounds at high temperature [27]. A study by Z. Hou et al. [31] reported that anthocyanins degraded quickly by using high temperatures and increased the $\mathrm{pH}$ at $100{ }^{\circ} \mathrm{C}$ and $\mathrm{pH}$ 5.0.

For evaluation of microbial properties, the selected young rice flake had water activity $0.189 \pm 0.003$, The product was not exceed the level from the microbial standard of Thai Industrial Standard No. 315-2548.

Table 2 Physical, chemical and microbial properties of young rice grain and rice flake

\begin{tabular}{|c|c|c|}
\hline \multicolumn{1}{|c|}{ Properties } & $\begin{array}{c}\text { Young rice } \\
\text { grain }\end{array}$ & $\begin{array}{c}\text { Young rice } \\
\text { flake }\end{array}$ \\
\cline { 2 - 3 } & Mean \pm SD & Mean \pm SD \\
\hline Physical properties * & $26.10 \pm 0.32$ & $44.79 \pm 0.36$ \\
$L^{*}$ & $1.05 \pm 0.06$ & $1.46 \pm 0.01$ \\
$a^{*}$ & $7.61 \pm 0.35$ & $12.17 \pm 0.16$ \\
$b^{*}$ & $0.560 \pm 0.003$ & $0.189 \pm 0.003$ \\
Water activity & & \\
\hline Chemical properties & $9.95 \pm 0.17$ & $4.25 \pm 0.13$ \\
Moisture content (\%)* & $6.98 \pm 0.57$ & $6.14 \pm 0.48$ \\
Protein (\%) & & $0.004 \pm 0.001$ \\
Fat (\%)* & $0.11 \pm 0.002$ & $0.92 \pm 0.17$ \\
Ash (\%)* & $1.43 \pm 0.12$ & 88.686 \\
Carbohydrate (\%) & 81.53 & \\
\hline Bioactive compound & & $2 \times 10$ \\
Total Phenolic & $347.965 \pm 81.522$ & $280.930 \pm 3.995$ \\
)mg GAE/g)* & & \\
\hline Antioxidant activity & $368.455 \pm 50.099$ & $254.158 \pm 7.644$ \\
DPPH (mg TE/g)* & $209.037 \pm 8.736$ & $123.172 \pm 3.137$ \\
FRAP )mg TE/g)* & $486.018 \pm 40.818$ & $372.2983 \pm 3.334$ \\
ABTS (mg TE/g)* & & \\
\hline Microbial properties & & \\
Total plate counts & $1 \times 10^{3}$ & $2 \times 10^{2}$ \\
(CFU/g) $_{\text {Yeast-molds (CFU/g) }}^{*}$ & & \\
\hline
\end{tabular}

Data were presented as mean values. * Significant difference of young rice grain compared between young rice flake (1:5 ratio of grain to water, $0.5 \mathrm{rpm}$ drum speed at $120^{\circ} \mathrm{C}$ ) is using paired Student's t-test $(\mathrm{p}<0.05)$ for data analysis.

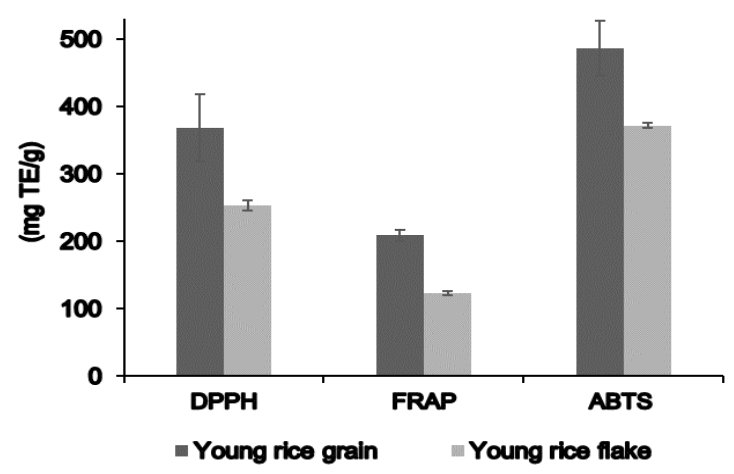

Fig. 3. Antioxidant activity against DPPH, FRAP and ABTS of young rice grain and rice flake.

\section{Conclusion}

Young rice grains contain the high nutritional value. Harvesting rice grains at the early stage might be an alternative process for the conservation of resources. 
However, the high nutritional properties of immature rice grains may lead to shorter shelf life, colour changing, microbial contamination, and compromise the marketing value. Therefore, from this perspective, preservation and value-added agricultural products have major concerns. Drying has been known as one of the best methods for preserving raw materials and limiting food waste and loss of agricultural products. Dehydration process using drum dryer technology is suitable for slurry form, low economics costs and low energy consumption. The finding of this study demonstrated that there were four optimal conditions (the treatments No. 1, 2, 4 and 5) for producing the immature kernel flake. We selected one of the optimal treatments with ratios of young rice grain to water at 1:5 w/w with $0.5 \mathrm{rpm}$ drum rotation speed to be the representative of the flake product due to the lowest water activity. The selected treatment of young rice flake had $0.189 \pm 0.002$ water activity and $4.250 \pm 0.130 \%$ moisture content. The color values of $\mathrm{L}^{*}, \mathrm{a}^{*}$ and $\mathrm{b}^{*}$ were $44.790 \pm 0.360, \quad 1.460 \pm 0.010$ and $12.170 \pm 0.160$, respectively. The proximate analysis was $0.004 \pm 0.001 \%$ fat, $6.140 \pm 0.480 \%$ protein, $0.920 \pm 0.170 \%$ ash, $88.686 \%$ carbohydrate. The total plate counts and yeast-molds in the milky rice flake were below the maximum standard. The total phenolic content and antioxidant capacity of rice flake were decreased after drying. Total phenolic content of the flake was $280.930 \pm 3.995 \mathrm{mg}$ GAE/g) and antioxidant activities; DPPH, FRAP and ABTS were $254.158 \pm 7.644,123.172 \pm 3.137$ and $372.298 \pm 3.334 \mathrm{mg}$ $\mathrm{TE} / \mathrm{g}$, respectively. These results indicate that young rice flakes were produced by drum dryer, have a great nutritional value retention which might has potential in the food industry and sustainable development of rice products.

\section{Acknowledgments}

This research was funded by King Mongkut's University of Technology North Bangkok. Contract no. KMUTNB-61DRIVE-020.

\section{References}

1) O. Napasintuwong. Rice Economy of Thailand. Agricultural and Resource Economics Working Paper No. 2562/1 (January 2019). Department of Agricultural and Resource Economics, Faculty of Economics, Kasetsart University, Bangkok, Thailand (2019): 1-36

2) T. Pantoa, M. Kubota, P. Suwannaporn, M. Kadowaki. Characterization and bioactivities of young rice protein hydrolysates, Journal of Cereal Science, 95 (2020): 103049

3) S. Jiamyangyuen, N. Nuengchamnong, P. Ngamdee. Bioactivity and chemical components of Thai rice in five stages of grain development, Journal of Cereal Sciences, 74 (2017): 136-144

4) S. Ngamsuk, J.L Hsu, T-C. Huang, P. Suwannaporn. Ultrasonication of milky stage rice milk with bioactive peptides from rice bran: Its bioactivities and absorption food and bioprocess technology, 3 (2020): 462-474
5) S. Butsat, N. Weerapreeyakul, S. Siriamornpun. Changes in phenolic acids development, J. Agric. Food Chem, 57 (2009): 4566-4571

6) P.Y. Lin, H.M. Lai. Bioactive compounds in rice during grain development, Food Chemistry, 127, 1 (2011): 86-93

7) T. Pantoa, I. Jones, P. Suwannaporn, M. Kadowaki, M. Kubota, S. Roytrakul, E.N. Clare Mills. Young rice protein as a new source of low allergenic plantbase protein, Journal of Cereal Science, 93 (2020): 102970

8) Future market insights. (2021, June 15). Instant cereals Market: Global Industry Analysis and Opportunity Assessment 2017-2027. https://www.futuremarketinsights.com/reports/instant -cereals-market

9) The insight partner. (2021, June 15). Market research reports. Porridge Market Forecast to 2028 - Covid-19 Impact and Global Analysis - by Type (Oat, Maize, Wheat, Rice, Millet); Distribution Channel (Supermarkets and Hypermarkets, Convenience Stores, Specialty Stores, Online) and Geography. https://www.theinsightpartners.com/reports/porridgemarket

10) K. Srikaeo, P.A. Sopade. Functional properties and starch digestibility of instant Jasmine rice porridges, Carbohydrate Polymers, 82, 3 (2010): 952-957

11)W. Jittanit, M. Chantara-In, T. Deying, W. Ratanavong. Production of tamarind powder by drum dryer using maltodextrin and Arabic gum as adjuncts. Songklanakarin Journal of Science and Technology. 33, 1 (2011): 33-41

12)M. Majzoobi, M. Radi, A. Farahnaky, J. Jamalian, T. Tongtang, Gh. Mesbahi. Physicochemical Properties of Pre-gelatinized Wheat Starch Produced by a Twin Drum Drier, Journal of Analytical Science and Technology, 13, 2 (2011): 193-202

13)C. Córdova, J. P. Vivanco, J. Quintero, A. Mahn. Effect of drum-drying conditions on the content of bioactive compounds of broccoli pulp, Foods, 9, 9 (2020): 1224

14)A. S. Mujumdar (Ed). Principles, classification, and selection of dryers. In Handbook of industrial drying. (Taylor \& Francis Group. LLC, New York, 2006)

15)F. H. Cosme-De Vera, A. N. Soriano, N. P. Dugos, R. V. C. Rubi. A comprehensive review on the drying kinetics of common tubers, J.asep, 14, 2 (2021): 146-155

16) K. Ruttarattanamongkol, S. Chittrakorn, M. Weerawatanakorn, N. Dangpium. Effect of drying conditions on properties, pigments and antioxidant activity retentions of pretreated orange and purplefleshed sweet potato flours, Journal of Food Science and Technology. 53, 4 (2016): 1811-1822

17)P. Wiriyawattana, S. Suwonsichon, T. Suwonsichon. Effects of drum drying on physical and antioxidant properties of riceberry flour, Agriculture and Natural Resources, 52 (2018): 445-450

18)P. Ngammuangtueng, N. Jakrawatana, P. Nilsalab, S. H. Gheewala. Water, energy and food nexus in rice production in Thailand, Sustainability, 11, 5852 (2019): 1-21 
19)N. V. Hung, M. V. Migo, R. Quilloy, P. Chivenge, M. Gummert. Life cycle assessment applied in rice production and residue management. In $\mathrm{M}$. Gummert, N. V. Hung, P. Chivenge, B. Douthwaite (Eds). Sustainable Rice Straw Management. (Springer, Cham, 2020)

20)R. A. Anderson, H. F. Conway, A. J. Peplinski. Gelatinization of corn grits by roll cooking, extrusion cooking and steaming, Cereal Science Today, 14 (1969): 14-12

21)O. Folin, V. Ciocalteu. Tyrosine and tryptophane determinations in proteins. Journal of Biological Chemistry, 73 (1927): 627-650

22)W. Daiponmak, C. senakun, S. Siramornpun. Antiglycation capacity and antioxidant activities of different pigmented Thai rice, International Journal of Food Science and Technology, 49 (2014): 18051810

23)I. F. Benzie, J.J. Strain. Ferric reducing/antioxidant power assay: Direct measure of total antioxidant activity of biological fluids and modified version for simultaneous measurement of total antioxidant power and ascorbic acid concentration, Methods Enzymology, 18 (1999): 15-27

24)R. Re, N. Pellegrini, A. Proteggente, A. Pannala, M. Yang, C. Rice-Evans. Antioxidant activity applying an improved ABTS radical cation decolorization assy, Free Radical Biology and Medicine, 26 (1999): 1231-1237

25)N. Yousf, F. Nazir, Rehana Salim, Hafiza Ahsan and Adnan Sirwal. Water solubility index and water absorption index of extruded product from rice and carrot blend, Journal of Pharmacognosy and Phytochemistry, 6, 6 (2017): 2165-2168

26)X. Qi , L. Chenga , X. Lia, D. Zhang, G. Wua , H. Zhanga, , L. Wanga, H. Qiana, Y. Wang. Effect of cooking methods on solubility and nutrition quality of brown rice powder. Food Chemistry, 274, 15 (2019): 444-451

27) Y. Gat, L. Ananthanarayan. Effect of extrusion process parameters and pregelatinized rice flour on physicochemical properties of ready-to-eat expanded snacks, Journal of Food Science and Technology, 2, 5 (2015): 2634-2645

28)W. Jittanit, C. Lalitmassakul, P. Charn-Utsar. Quality of instant congee and energy consumption in the drying process by Using Drum Dryer. The Journal of KMUTNB, 22, 2 (2012): 256-264

29)A. Patras, N.P. Brunton, C. O'Donnell, B.K. Tiwari. Effect of thermal processing on anthocyanin stability in foods; Mechanisms and kinetics of degradation, Trends in Food Science and Technology, 21 (2010): 3-11

30)W. Daiponmak, C. Senakun, S. Siriamornpun. Antiglycation capacity and antioxidant activities of different pigmented Thai rice, International Journal of Food Science and Technology, 49 (2014): 18051810

31)Z. Hou, P. Qin, Y. Zhang, S. Cui, G. Ren. Identification of anthocyanins isolated from black rice (Oryza sativa L.) and their degradation kinetics, Food Research International., 50 (2013): 691-697 